\title{
The Effect of the Over Voltage on the Stress \\ Distribution at the Terminals of H.V. XLPE Cables
}

Saad S. Sheet / Ass. Lecturer

Farook k. Amouri /

Professor

saadmsc@yahoo.com

amouri 2006@yahoo.com

\begin{abstract}
The power cables are usually subjected to over voltages from lightning impulses and switching surges, such over- voltages effects are concentrated at terminals of the high voltage cables .

The longitudinal and radial stresses through cable terminals are computed by using Schwarz christoffel transformation used for sketching the electrical fields.

The investigated cables are of rated voltage $33 \mathrm{Kv}$ and $132 \mathrm{Kv}$ insulated by cross-linked polyethylene (XLPE).

Electrical field sketching at the cable terminals is carried out theoretically by the aids of computer programs. The results give an indication of the maximum stresses occurs in the cables insulation at the terminals and the maximum longitudinal stresses along the cables screen at outer surface of the XLPE insulation. The results show that maximum stress occurred by lightning impulse is found much higher than that of switching operation but the later has longer period. And both are found depends on the polarity of the over voltages and the polarity of the (power/frequency) voltages.
\end{abstract}

Keywords: stress distribution ofover voltage XLPE cables, termination of XLPE cables

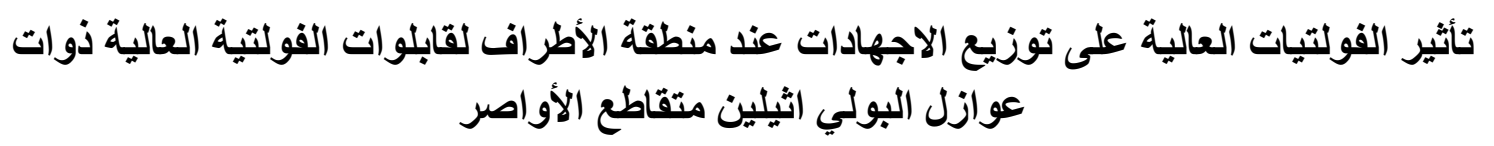




\section{سعد صاموئيل شيت}

الكلية التقنية

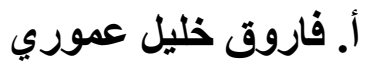

الهندسة الكهربائية

/الموصل

\section{الخلاصة}

قابلو ات القدرة تتعرض عادة لفولتيات عالية ناتجة من نبضـات الاندفاعة ونبضـات الفتح و الغلق. مثل هذه الفولتيات العالية تتركز بمقادير عالية في منطقة الأطراف لقابوات التات الفولتية العالية. تم حساب ورسم المجال الكهربائي الطولي و القطري عند منطقة الأطر اف بتطبيق نظريـة تحويلة التو افق (تحويلة شو ارتز كرستوفل).

اختبر القابلو المستخدم والذي تم تطويره بتقنين الأول 33 كيلو فولت أما الثاني فهو 132 كيلو فولت وذو عازل صلب من نوع البولي اثيلين متقاطع الأواصر.

حسابات مخططات المجال الكهربائي عند منطقة الاطر اف تمت وتنفيذها بصورة نظريـة باستخدام

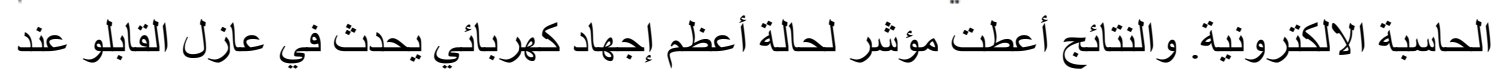

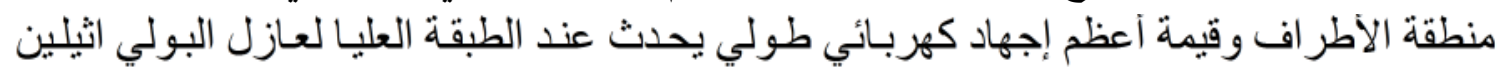

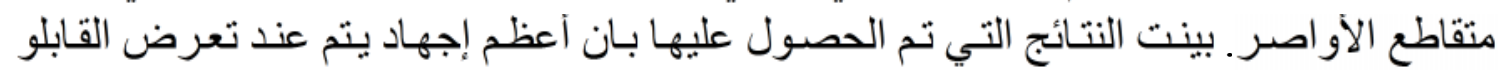

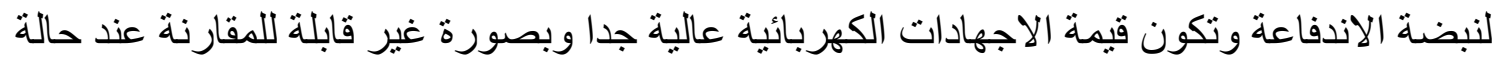

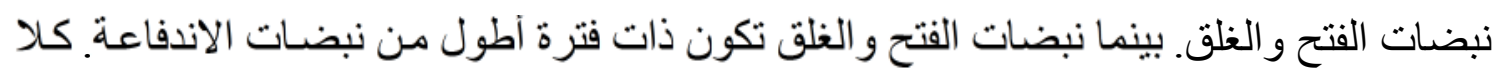

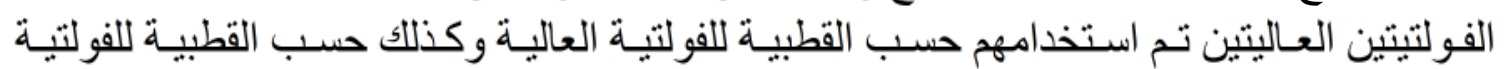
الاعتيادية التي يعمل عندها القابلو قبل تعرضه إلى الفولتئل التيات العالية. 
The cross-linked high density polyethylene is used as the insulating material in medium voltage cables $(3.3 \mathrm{Kv}, 6.6 \mathrm{Kv}, 11 \mathrm{Kv}, 33 \mathrm{Kv}, 66 \mathrm{Kv})$, high voltage cables $(110 \mathrm{Kv}, 132 \mathrm{Kv}, 220 \mathrm{Kv}, 400 \mathrm{Kv})$, and at present time used for more than $400 \mathrm{Kv}$. Joints and termination in such cables are the most risky parts in the cables system. This is because it is not easy to get a purely uniform electric field in such positions even at power frequency voltages. High voltage cables are often connected with over head transmission lines, and so such cables are subjected to over voltages from lightning impulse as well as the over voltages from switching operation of the power transmission system. High voltage cables in underground power systems usually tested with lightning impulses according to the applicable (IEC) standard to proof it's capability against lightning over voltage ${ }^{[1]}$.

High voltage switching operation and discharge phenomena in the gas gap circuit breakers electrodes cause, electromagnetic transients and such transients produced high electromagnetic fields and cause an over lap and concentration of electric fields specially at cable terminations ${ }^{[2,3]}$.

Contribution deals with maximum stresses and field concentration at cable termination and at over voltages are produced in this paper. The contribution involves a field sketching at cable termination using Schwarz Christoffel transformation.

\section{Theoretical Approach:}

At rated working A.C. voltages on a cable and at over voltages the stress can be given by the following equations [4].

The stress near conductor $\mathrm{E}_{\mathrm{r}}$ is:

$\mathrm{E}_{\mathrm{r}}=\left(\mathrm{V}+\mathrm{V}_{\mathrm{o.v}}\right) /(\mathrm{r} \ln (\mathrm{R} / \mathrm{r}))$ 
The stress near sheath $E_{R}$ is:

$\mathrm{E}_{\mathrm{R}}=\left(\mathrm{V}+\mathrm{V}_{\mathrm{o.v}}\right) /(\mathrm{R} \ln (\mathrm{R} / \mathrm{r}))$

Where V: Working voltage in $\mathrm{Kv}$ at real value.

$\mathrm{V}_{\text {o.v }}$ : Over voltages at real value.

r: Radius of conductor in meter.

$\mathrm{R}$ : Radius of sheath in meter

The above two equations at the peak value of the electrical stresses can be defined at the conductor and at the sheath in case of no-load and at full load. The peak value of the stress near the sheath is higher than that near the conductor.

At the cable terminals the electric field or stress seems to be nonuniform and this is due to the presence of the longitudinal fields in addition to the radial fields.

In order to declare the effect of the two electrical fields at cable terminal, the field sketching at cable terminal is carried out theoretically at over voltage imposed on the working power/frequency voltages.

Sketching of the electric field at cable terminals is carried out by using Schwarz Christoffel transformation, such method was used in reference [3] and verified by experiments at (power/frequency) voltages [3]. The general form of this transformation is:

$\frac{d Z}{d W}=S(W-a)^{\frac{\alpha}{\pi}-1}(W-b)^{\frac{\beta}{\pi}-1}(W-c)^{\frac{\gamma}{\pi}-1}(W-d)^{\frac{\delta}{\pi}-1}$ 
where:

S: rotation constant.

$\mathbf{a}, \mathbf{b}, \mathbf{c}, \mathbf{d}$ : values on the real axis used to ensure transformation conditions.

$\alpha, \beta, \gamma, \delta$ : right or zero angle of the polygon.

By using this method any polygon in Z-plane can be transformed to the upper half of W-plane. The polygon sides of Z-plane became the real axis of the W-plane as shown in figure(1).

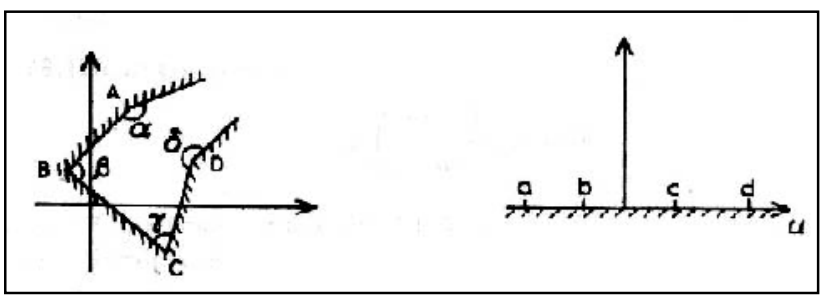

figure(1)

Representation of Schwarz Christoffel transformation

The values A, B, C, D shown in figure(1) are representing the vertices of the polygon.

For a certain cable two angle are used, the first $\alpha=2 \pi$, and the second $\beta=0$, as shown in figure(2) and the representation of Z-plane and W-plane both :

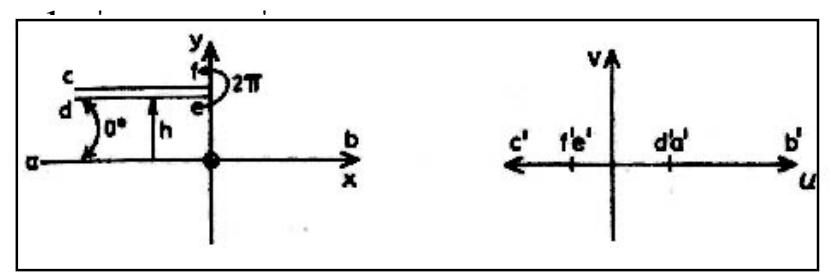


figure(2)

Representation of Schwarz Christoffel transformation for cable termination

The above equation will be:

$\frac{d Z}{d W}=S(W-a)^{\frac{\alpha}{\pi}-1}(W-b)^{\frac{\beta}{\pi}-1}$

$a, b$ represents the value of located to assure the transformation condition of $(a=-1)$, and $(b=0)$, and the equation will be:

$Z=S(W+\operatorname{In} W)+K$

the two unknown values $S \& K$, can be used as:

$S=K=\frac{h}{\pi}$

where h: conductor radius

so that the equation will be: 
$Z=\frac{h}{\pi}(W+\operatorname{In} W+1)$

This equation represents the form of the equipotential lines. under transformation condition and the arrangement in the above form is a new form of equation wich can be developed as:

$Z=\frac{h}{\pi}\left(e^{\omega}-\omega+j h\right)$

This equation represents the form of the flux lines.

By representing the real and imaginary parts from the above equation and plotting, then the field distribution around the cable conductors can be defined.

The field map representation for cable termination by using method of Schwartz Christoffel transformation given in figure (3).

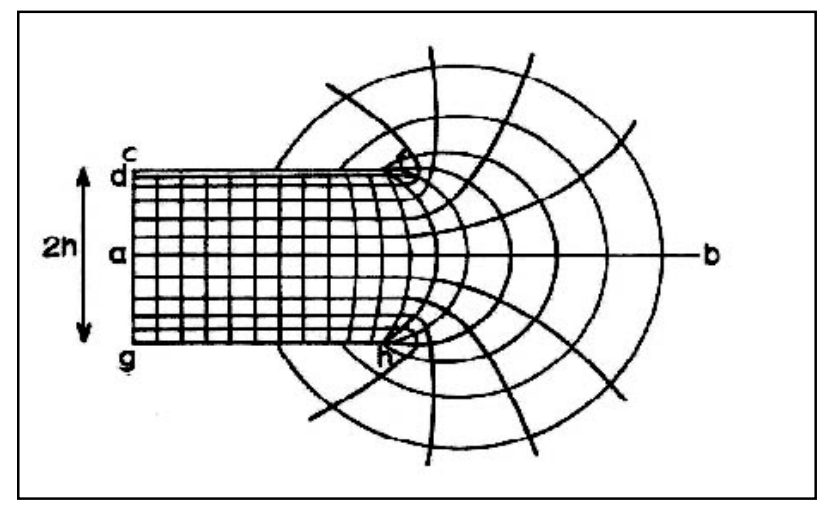

figure(3) 
field map representation for cable termination

\section{Designed Program:}

The theoretical analysis is simulated by designing a computer program. The program used data of high voltage power cables rated at voltages of $33 \mathrm{Kv}, 132 \mathrm{Kv}$. The simulation involve the use of lightning impulses of 1.2/50 $\mu \mathrm{s}$ and at peak values of 20 times that of working voltages and at both positive and negative impulses. For switching operation, the waveforms of the surges is at peak value of 4 times that of working voltage and at longer front and tail voltage $20 / 30 \mu$ s, this value is computed by varying the values of the impulse generator parameter $\left(\mathrm{R}_{1}, \mathrm{R}_{2}, \mathrm{C}_{1}, \mathrm{C}_{2}\right)$. The designed computer programs is given by its flow chart is shown in figure (4).

\section{Results and Discussion:}

Over voltages subjected on high voltage power cables are usually of two main forms, the first one is the impulse produced form lightning strokes and these are either positive or negative. Simulation of the positive and negative impulse waveform which are chosen and applied in the present study are given in figure(5) for $33 \mathrm{Kv}$. The positive impulse voltages imposed on the positive (power/frequency) cycle is given in figure(5) - (case a) and the corresponding fields at cable terminal is given figure(5) - (case e). similar simulation for positive impulse voltages imposed on negative (power/frequency) cycle is given in figure(5) - (case b), and the corresponding field sketching at cable terminal is shown in figure(5) (case f). The negative impulse imposed on positive power cycle as given in figure (5) - (case c) and it's corresponding field sketching at cable terminal is shown in figure(5) - (case g). The negative impulse imposed on negative (power/frequency) cycle with it's field sketching are given in (case d) and 
(case h). The calculated results from the field sketching in figure(5) indicate that maximum field concentration occurred at positive impulse imposed on negative (power/frequency) cycle, (case b) followed by the case negative impulse imposed on positive cycles, (case c), negative impulse imposed on negative (power/frequency) cycle, (case d) and positive impulse imposed on positive (power/frequency) cycle, figure (case a). Similar results are obtained in figure(6) were for $132 \mathrm{Kv}$ cable terminal and also at positive and negative imposed impulses on (power/frequency) voltages. As compared with $33 \mathrm{Kv}$ cable the only difference in found in the amplitude of the (power/frequency) voltages since it is higher in $132 \mathrm{Kv}$ cables, but for $33 \mathrm{Kv}$ the field concentration due impulse is more risky because the insulation thickness is less. As a result of this study the termination in $33 \mathrm{Kv}$ must be designed depending on the impulse withstand level. The design of lower level terminals in $33 \mathrm{Kv}$ is the main cause of the $33 \mathrm{Kv}$ termination failure. With switching operation at $33 \mathrm{Kv}$ cable termination, the surge voltage imposed on negative (power/frequency) voltage cycle (case b) results the most field concentration followed by (case d) of negative surge imposed on negative power cycle followed by (case c) of negative surge imposed on positive (power/frequency) and finally (case a) of positive surge imposed on positive power cycle. For $132 \mathrm{Kv}$ terminal at switching operation the results given in figure(7) and for the above four different cases are similar in form to that at $33 \mathrm{Kv}$ cable terminals. 


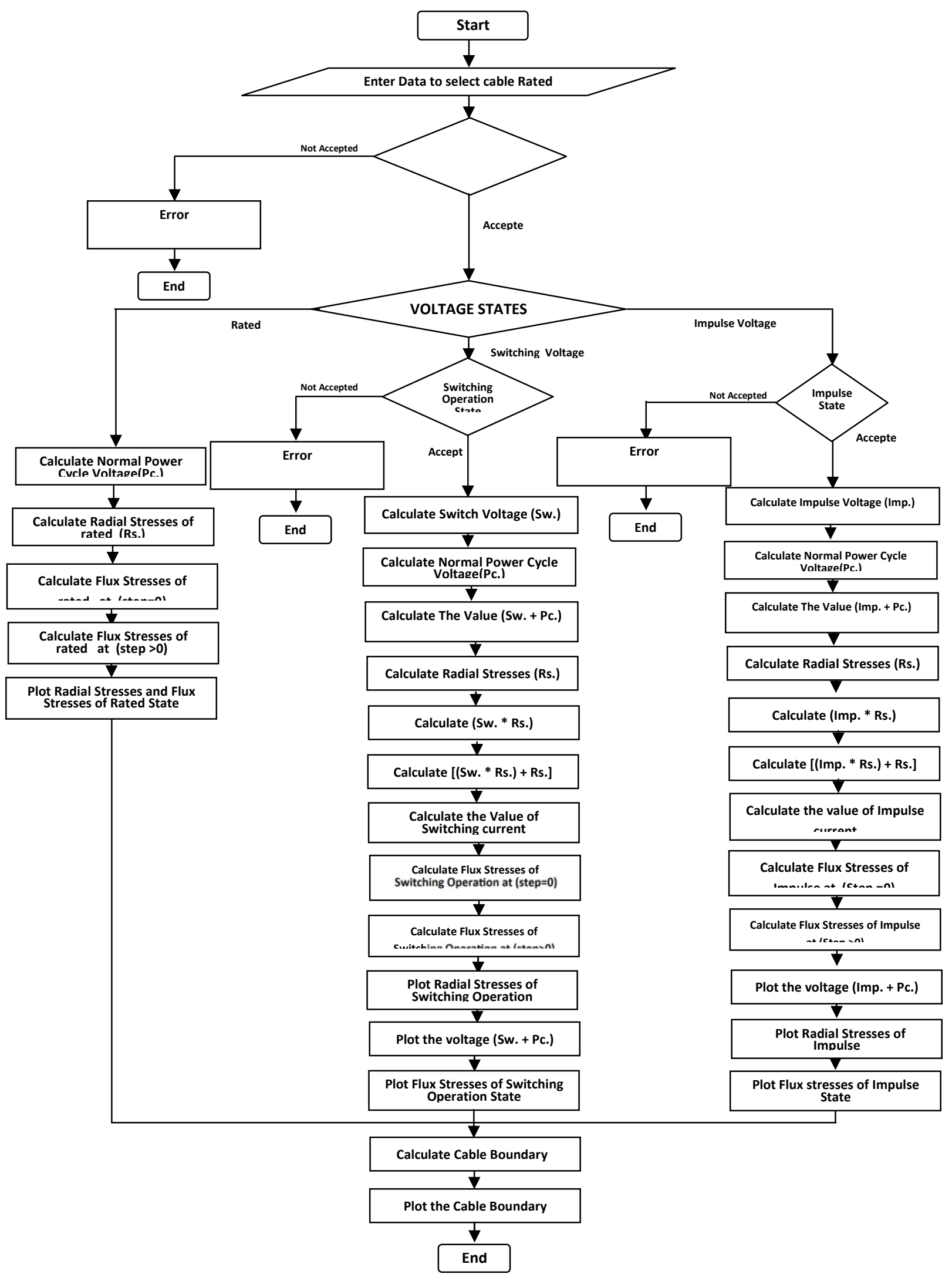


Amouri : The Effect of the Over Voltage on the Stress Distribution at the Terminals 
figure(4) flowchart of the designed program

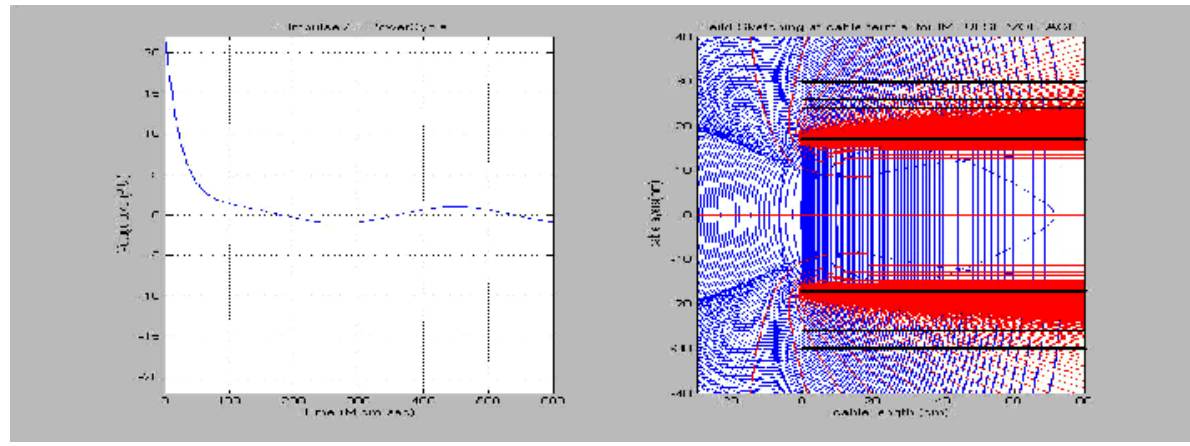

(a)

(e)

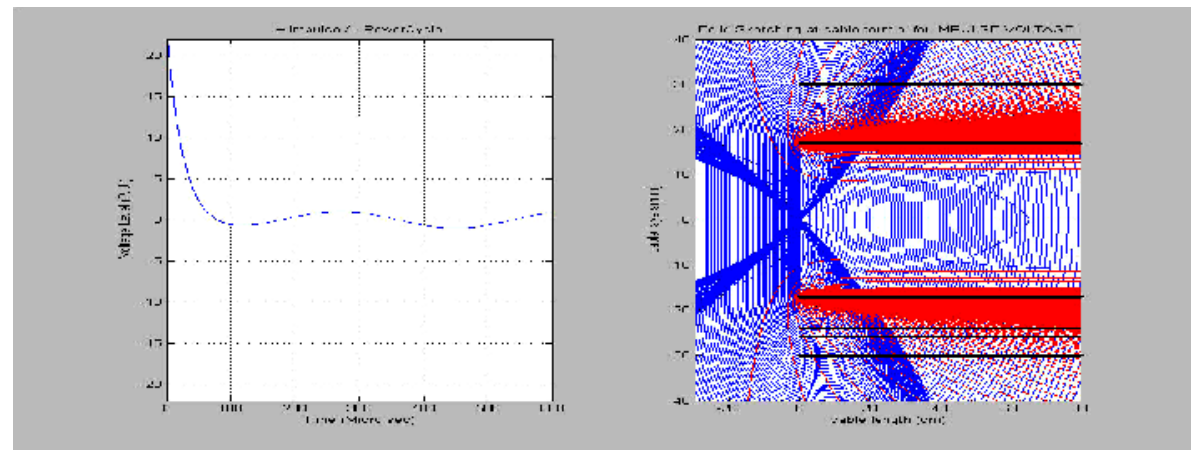

(b)

(f) 

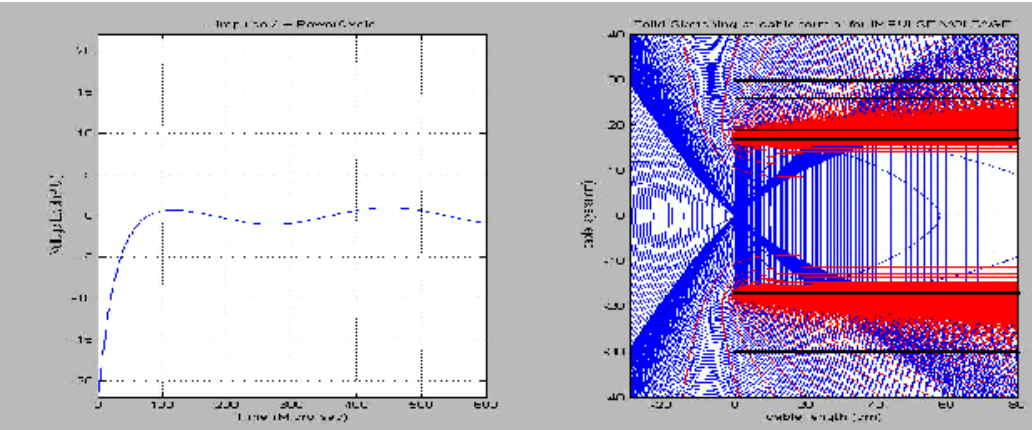

(c)

$(\mathrm{g})$

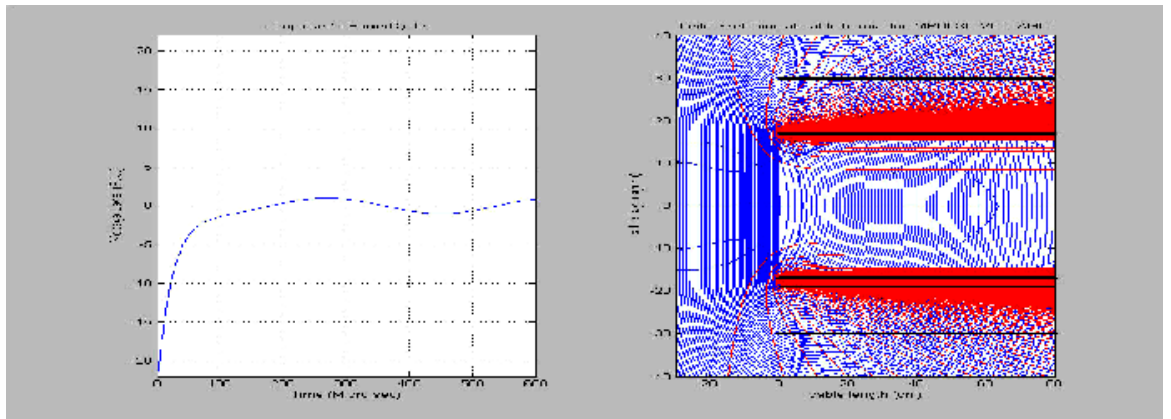

(d)

(h)

figure(5)

$a, b, c, d$, are wave forms of the imposed impulse waveforms on power/frequency voltage

$\mathrm{e}, \mathrm{f}, \mathrm{g}, \mathrm{h}$ are the field sketching for $\mathrm{a}, \mathrm{b}, \mathrm{c}, \mathrm{d}$ cases in $33 \mathrm{Kv}$ power cable terminal

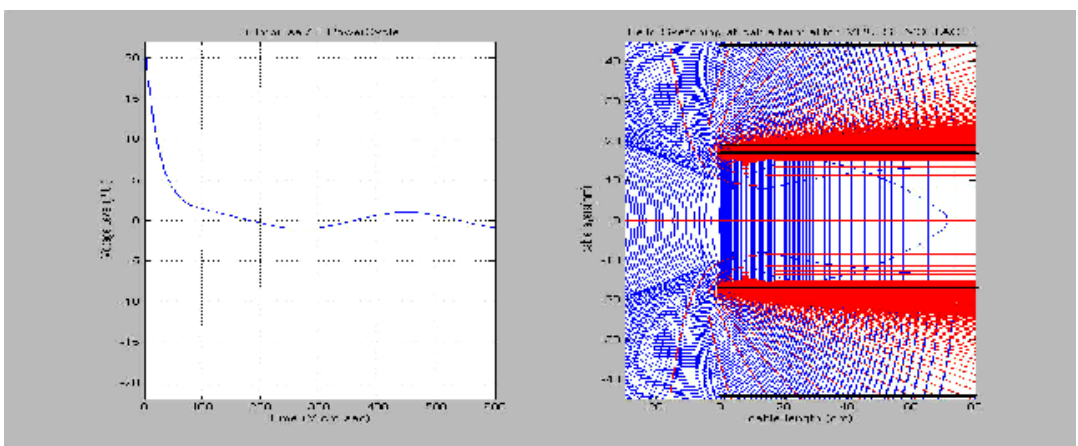

(a)

(e) 


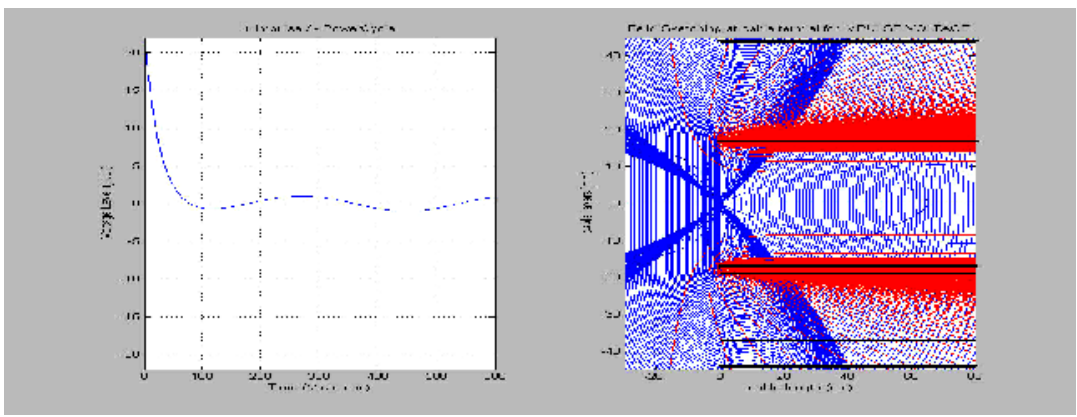

(b)

(f)

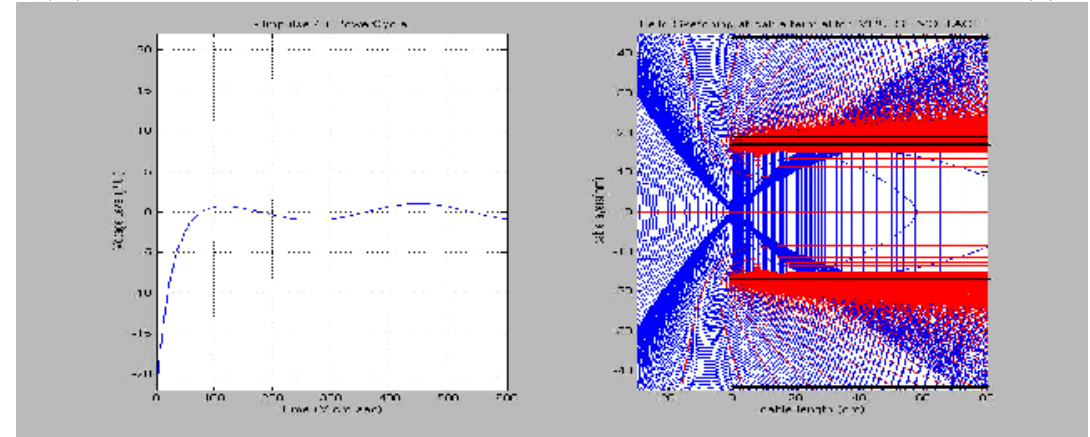

(c)

$(\mathrm{g})$

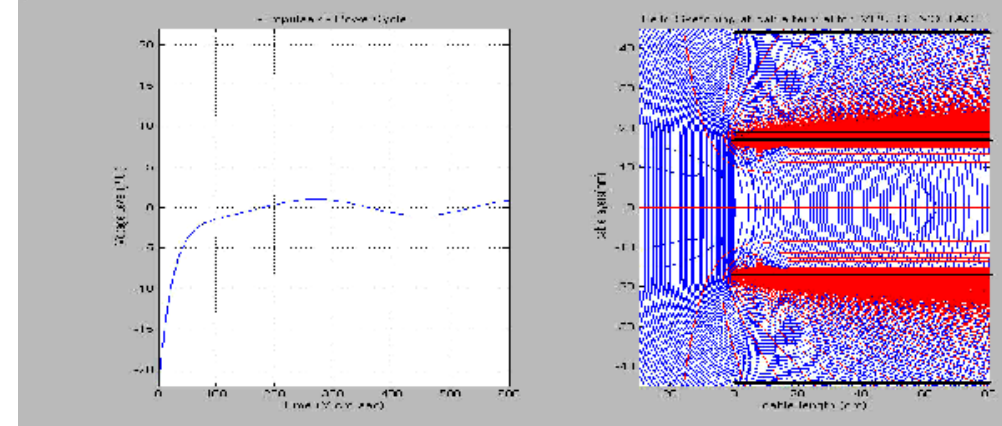

(d)

(h)

figure(6)

$\mathrm{a}, \mathrm{b}, \mathrm{c}, \mathrm{d}$, are wave forms of the imposed impulse waveforms on power/frequency voltage

$\mathrm{e}, \mathrm{f}, \mathrm{g}, \mathrm{h}$ are the field sketching for $\mathrm{a}, \mathrm{b}, \mathrm{c}, \mathrm{d}$ cases in $132 \mathrm{Kv}$ power cable terminal 


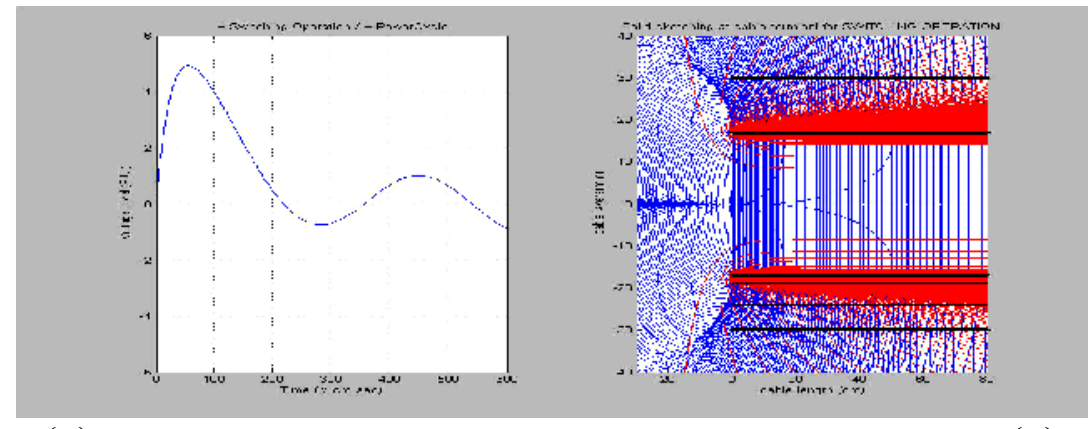

(a)

(e)
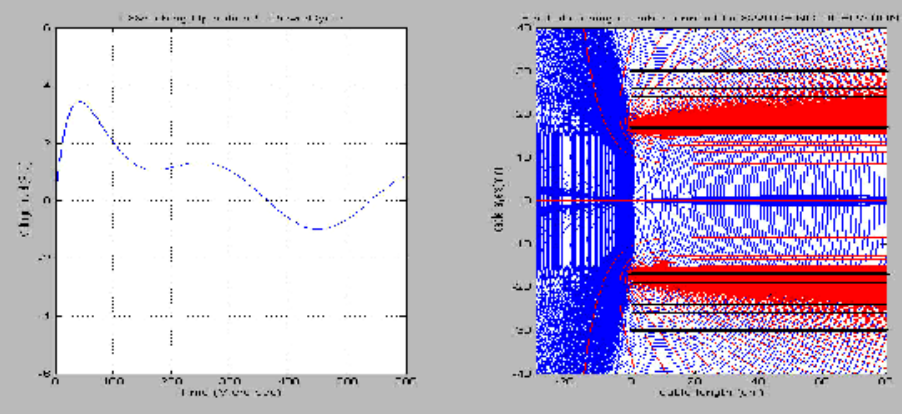

(b)

(f)

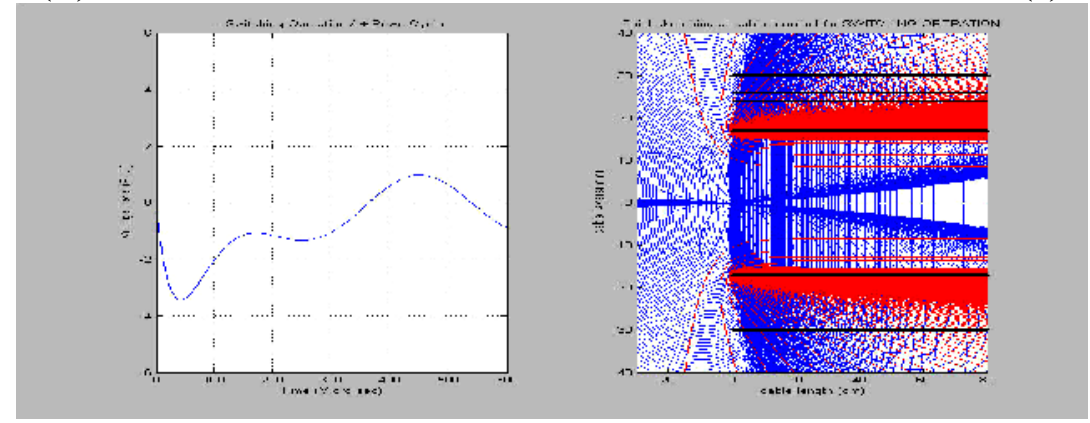

(c)

$(\mathrm{g})$
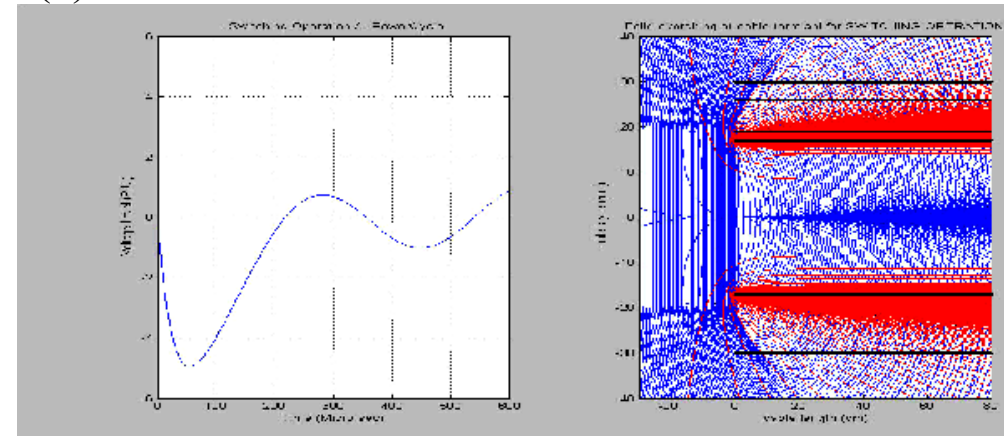

(d)

(h)

figure(7)

$a, b, c, d$, are wave forms of the imposed switching operation surges on power/frequency voltage

$\mathrm{e}, \mathrm{f}, \mathrm{g}, \mathrm{h}$ are the field sketching for $\mathrm{a}, \mathrm{b}, \mathrm{c}, \mathrm{d}$ cases in $33 \mathrm{Kv}$ power cable terminal 


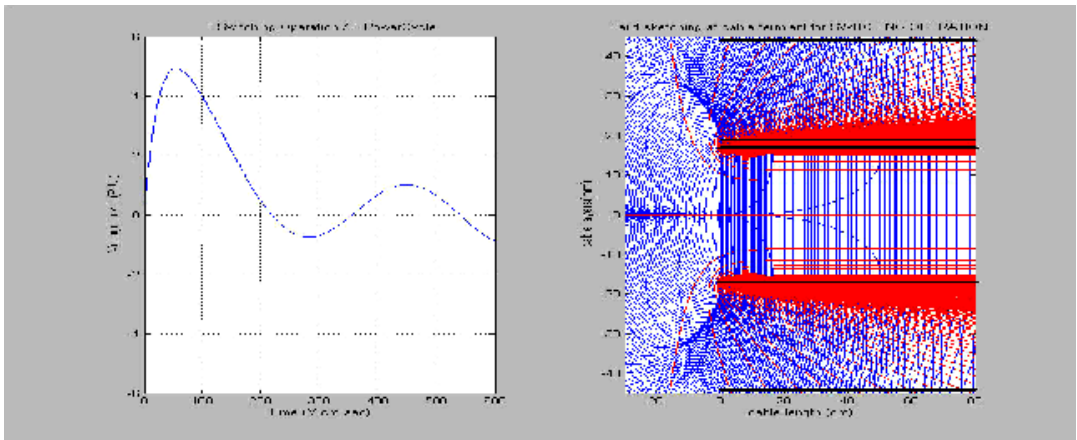

(a)

(e)

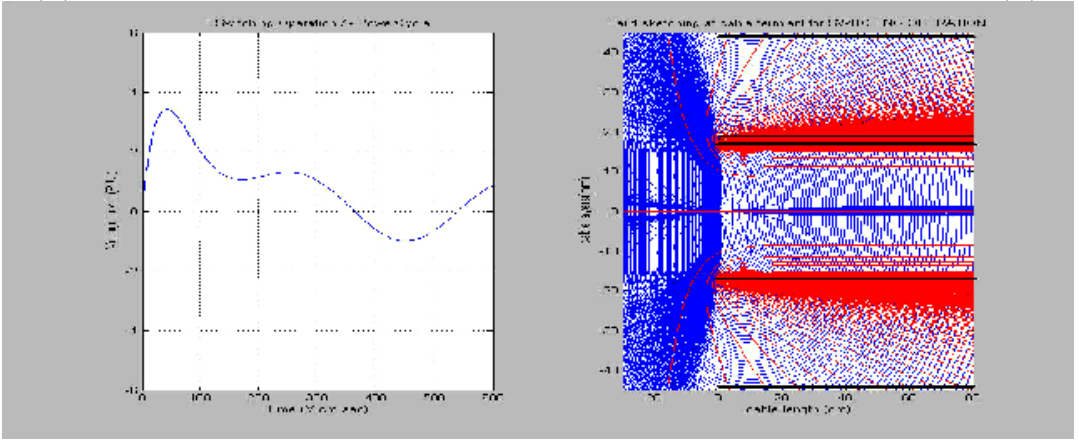

(b)

(f)
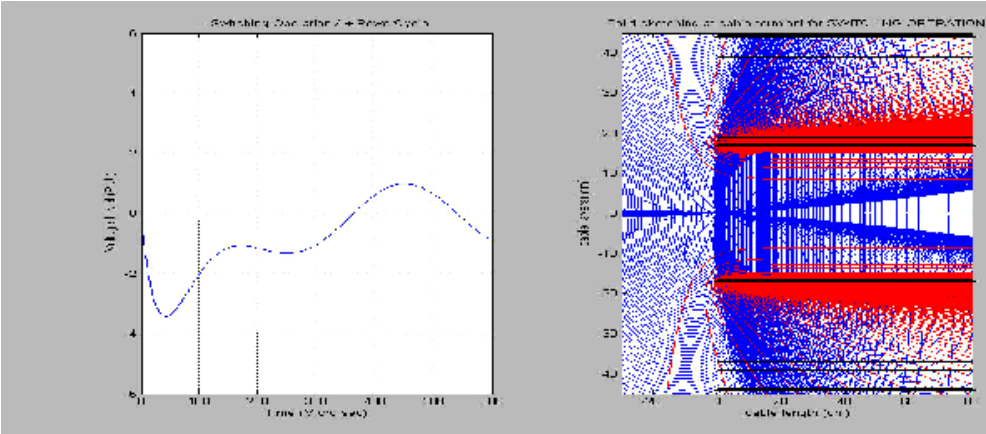

(c)

$(\mathrm{g})$ 


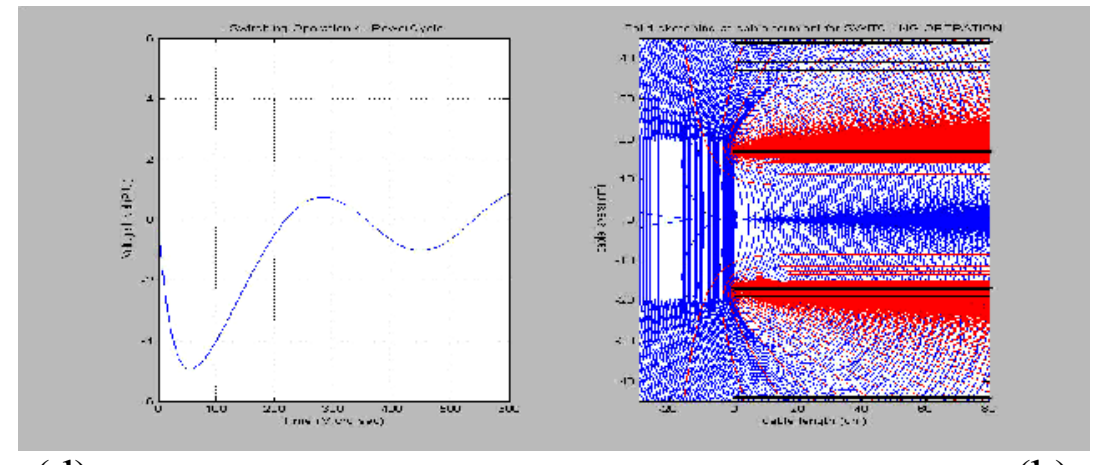

(d)

figure( 8 )

(h)

$a, b, c, d$, are wave forms of the imposed switching operation surges on power/frequency voltage

$\mathrm{e}, \mathrm{f}, \mathrm{g}, \mathrm{h}$ are the field sketching for $\mathrm{a}, \mathrm{b}, \mathrm{c}, \mathrm{d}$ cases in $132 \mathrm{Kv}$ power cable terminal

\section{Conclusion:}

Field concentration in high voltage cables subjected to over voltage imposed on power/frequency voltage indicates a very concentrated electrical field at cable terminals and this is found depends on the polarity of the (power/frequency) voltages. Such difference becomes very serious due to the variation in polarity of the (power/frequency) voltages specially in the cable insulators. In XLPE cable insulators the change in the space charge accumulation followed concentrated electrical field usually lag the variation in polarity and cause more space charge accumulation and more field concentration. Over voltage effect on $132 \mathrm{Kv}$ cable terminals is found to be nearly in the same manner as that for $33 \mathrm{Kv}$ cable.

\section{References:}


1. Schwenk K. and Gamlin M. "Load range methods for lightning impulse testing with high voltage impulse generators", Haefly Test AG, Basel, Switzerland 2005.

e-mail: schwenk.klaus@haefely.com

2. Akses A., Yazici M., Kalenderli O. and Baran E. "Electromagnetic interface from a lightning impulse generator", Turkey 2002.

e-mail: aysam@uekae.tubitak.gov.tr

3. Sheet S. and Amouri F., "Electrical stress concentration at the terminals of M.V. and H.V. XLPE cables", Al-Rafidain Engineering Vo1.14, No.1, Iraq 2006.

e-mail: $\underline{\text { saad_msc@yahoo.com }}$

4. Weedy B.M., "Underground transmission", Handbook, John Wiley, England 1979.

5. Gallagher T. J. \& Pearmain A. J., "High Voltage testing and design", Handbook, university of London, John Wiley, England, 1984. 